\title{
Conspiracy theories on the basis of the evidence
}

\author{
M R. X. Dentith
}

August 23, 20I7

\begin{abstract}
Conspiracy theories are often portrayed as unwarranted beliefs, typically supported by suspicious kinds of evidence. Yet contemporary work in Philosophy argues provisional belief in conspiracy theories is at the very least understandablebecause conspiracies occur - and that if we take an evidential approach, judging individual conspiracy theories on their particular merits, belief in such theories turns out to be warranted in a range of cases.

Drawing on this work, I examine the kinds of evidence typically associated with conspiracy theories, and show how the so-called evidential problems with conspiracy theories are also problems for the kinds of evidence put forward in support of other theories. As such, if there is a problem with the conspiracy theorist's use of evidence, it is one of principle: is the principle which guides the conspiracy theorist's use of evidence somehow in error? I argue that whatever we might think about conspiracy theories generally, there is no prima facie case for a scepticism of conspiracy theories based purely on their use of evidence.
\end{abstract}

\section{Acknowledgements}

Thanks to Daniel Wilson, Lee Basham, Martin Orr, Richard Viskovic, and Tiddy Smith for feedback on an early draft of this paper, as well as the participants and audience at the SCIENCONS conference and workshop (November 20I6) at the University of Padova for feedback on elements which made it into this paper.

M R. X. Dentith was supported by a fellowship at the Research Institute of the University of Bucharest (ICUB). 


\section{Introduction}

There is, it is fair to say, a stigma against conspiracy theories in popular discourse. After all, there are an awful lot of theories about putative conspiracies and many of them - at least some of us think - are poorly evidenced.

Yet a conspiracy theory - if we break down the term into its constituent partsis just a theory about a conspiracy; to wit, a theory about two or more people working together in secret towards some end. This general, non-pejorative definition has been defended by philosophers like Brian L. Keeley (Keeley I999), Charles Pigden (C. R. Pigden in press), David Coady (Coady 2OI2), Lee Basham (Basham in press) and myself (Dentith 2OI4). Indeed, philosophers interested in the topic of belief in conspiracy theories (with few exceptions) have argued that you cannot principally assess conspiracy theories as a class but, rather, we must undertake such an analysis on a case-by-case basis. The prima facie suspicion of conspiracy theories generally, before assessing the particulars of individual theories, gets things back-tofront. Conspiracy theories - like any theory - should be assessed on their evidential merits.

As will be argued in this article, the kinds of evidence conspiracy theorists appeal to when proposing or defending their conspiracy theories are not that problematic when considered properly. If there is an issue with the evidence used in support of conspiracy theories, then it is an issue of principle: the evidence is being abused or just not being used appropriately. As such, this paper is both a survey of arguments in the philosophical literature concerning the way evidence is used to support belief in conspiracy theories, as well as a synthesis of those arguments. As we will see, there is no prima facie justification for a suspicion of the kinds of evidence conspiracy theorists are alleged to rely upon.

To show this we will examine the kinds of supposedly problematic evidence and evidential practices associated with conspiracy theories: from evidence manipulation and selection (section 2); errant data (section 3); claims of disinformation (section 4); how our judgements of prior probability inform our estimates about the existence of conspiracies now (section 4); to the role of secret evidence (section 5). We will see that the evidentiary principles of the conspiracy theorist are not problematic in the way some have tried to argue.

In the latter part of the paper we will examine some meta-evidential concerns, such as worries about the purported size of conspiracies (section ఫ) and information hierarchies (section 8), before concluding that-if we are suspicious of some conspiracy theory-we have to grapple with interesting evidential concerns before we can condemn belief in such a theory just because it has been labelled 'conspiratorial.' 


\section{I.I Conspiracy theorists}

When discussing conspiracy theories, it is hard to get around the discussion of 'conspiracy theorists,' which is typically taken to be a pejorative label. Now, as Charles Pigden argues, if we accept the claims of historical sources and contemporary media coverage, then we know conspiracies occur, and thus we are conspiracy theorists. If, however, we think those same sources are pure disinformation, then we believe in the existence of some conspiracy to cover up what is really happening, which in turn means we subscribe to some conspiracy theory. So, no matter what we believe about conspiracies, we are conspiracy theorists (C. R. Pigden in press).

Following that argument, whilst we are all conspiracy theorists, we are only conspiracy theorists with respect to particular conspiracy theories. That is, if we are historically or politically literate we are all conspiracy theorists, but we are not conspiracy theorists with respect to all conspiracy theories. As such, in this paper 'conspiracy theorist' will simply refer to someone who holds a particular conspiracy theory. That is, the label is relativised to some theory, rather than being a general appellation of pejorative character.

\section{Evidence Selection \& Manipulation}

People worry about the way in which conspiracy theorists present evidence for their conspiracy theories. When assessing the strength of any argument-particularly on a topic we are not well-informed about - we often worry we have not have been presented with everything that we need to know. For example, I might claim the reason I endorsed a candidate for a tenure-track position was because I believed they were the most suitably qualified, leaving out the fact that they offered me a substantial bribe to endorse them. This is an example of what we might term 'selectiveness.'

Selectiveness: The presentation of carefully selected propositions from a wider pool of evidence to make a candidate explanation look warranted when it otherwise might not be.

Take, for example, the various 9/II Inside Job hypotheses, which claim the September IIth, 200I attacks on New York and Washington, D.C. were committed by elements in the U.S. government. Conspiracy theorists of this ilk are often characterised as being selective in their use of evidence because:

a) their evidence is comprised of selected parts of the total evidence, and

b) by only citing a subset of that evidence, they erroneously conclude that the evidence strongly suggests 9/II was an inside job. 
There are two kinds of alleged selectiveness on the part of the conspiracy theorist here. The first is the selection of snippets of the total evidence. The second follows from the first: the framing of this evidential subset as strongly suggesting a particular conclusion.

Quassim Cassam - using the example of a fictional conspiracy theorist, Oliverputs this second kind of selectiveness down to the epistemic vice of gullibility on the part of conspiracy theorists generally. ${ }^{\text {B }}$ Oliver is said to be selective with his evidence: he insists that $9 /$ II 'had to be an inside job ...because aircraft impacts couldn't have brought down the towers (Cassam 20I5),' and he 'ignores important evidence which bears on his questions, relies on unreliable sources, jumps to conclusions and generally can't see the wood for the trees (Cassam 2016, p. I64).'

Yet selectiveness is a feature of almost any explanation because it is an activity associated with the presentation of evidence in explanations generally. As such, the worry about the selective use of evidence with respect to conspiracy theories must centre on the question of whether the subset of evidence was manipulated to suggest a conclusion that might not follow should we have access to the total evidence. That is, if there really is a problem with the selective use of evidence in conspiracy theories, then either conspiracy theorists are somehow overly prone to being selective, or the kind of selective evidence use we see in association with conspiracy theories is of a problematic kind.

Cassam would have us believe that conspiracy theorists are prone to being problematically selective in their evidence use because they are gullible. But note that Cassam's conspiracy theorist, Oliver, is not a real person; it is telling that Cassam has to create a conspiracy theorist out of whole cloth to show up the faults of conspiracy theorists generally, rather than work with an example from real life. After all, no matter our opinion about the plausibility of the various Inside Job hypotheses, even the most cursory examination of them provides us with examples of conspiracy theorists citing interesting pieces of evidence (many of which appear to be contrary to the official theory of the event, a topic we will return to in section [ 3 . So, even if we are to take Cassam's portrayal of Oliver seriously, then while Oliver may well indeed suffer from the epistemic vice of gullibility, it is not connected to him being a typical conspiracy theorist. People like Oliver may well exist in the Inside Job community, but Oliver-it is fair to say-is someone who is gullible who also just happens to be a conspiracy theorist about $9 / I I .^{\text {日 }}$

Indeed, if we are worried about conspiracy theorists selectively presenting their evidence, then we should also be worried about non-conspiracy theorists doing the same. Historians, for example, selectively cite evidence from the historical record,

${ }^{\mathrm{I}}$ Whilst Cassam seems willing to admit that conspiracies occur (see (Warburton and Cassam 2015)), he uses the terms 'conspiracy theory' and 'conspiracy theory' in the pejorative sense in the works discussed here.

${ }^{2}$ For another analysis of Cassam's work, see (C. R. Pigden 20I6). 
but they do this because:

a) citing all the available evidence would clutter their narrative, and

b) only some of the available evidence is salient.

It is the second point which underscores the idea that selectivity of evidence can be principled; for the Marxist historian the principle is something about the role of historical materialism in history; whilst for the advocate of the 'Great Individuals of History' thesis, the principle is something about individuals rising up above the masses. We see this in other domains: scientists select which pieces of evidence they take it are salient when engaging in research, ruling out data points which are unrelated to the phenomena being explored; social psychologists select which $\mathrm{p}^{\text {-values }}$ are salient to their models; and so on. In each of these cases, there is a principle involved which explains not just why the evidence has been selected, but also what counts as evidence. That is, the theoretical underpinnings of our inquiries informs our judgements about what even counts as salient evidence in these cases.

So, is the principle of selection by the conspiracy theorist pathological or illdefined? Well, a cursory glance at recent history presents us with a plethora of actual conspiratorial activity on the part of influential institutions. Now, if we assume conspiratorial activity is rare, then the principle behind the conspiracy theorist's selective citation of evidence would appear unmotivated. If we assume conspiracies are common-or just more common than not-then it seems reasonable for the conspiracy theorist to suspect and thus include conspiratorial hypotheses in the pool of potential best explanations for certain kinds of events (we will return to this issue in section 4.2). So, while we might be able to find reasons to call the principle of evidence selection by certain conspiracy theorists into question, the fact the selectiveness can be principled goes a long way to showing that its adherents are not acting irrationally.

Indeed, what makes the various 9/II Inside Job hypotheses interesting is that under the general definition of what counts as a conspiracy theory offered earlier, any explanation of 9/II turns out to be a conspiracy theory, whether or not you think the attacks were orchestrated by Al-Qaeda, or the U.S. The event was, after all, the result of secretive activity undertaken by a group, and that makes any theory about it a theory about a conspiracy (to wit, a conspiracy theory). As such, Cassam's Oliver can be easily contrasted with a story about Oliver's opposite-say, Oliviawho could be seen as being just as gullible when it comes to the official (conspiracy) theory of 9/II. After all, belief in the official theory of 9/II also relies upon the selection of evidence; in this case the evidence which purports to show Al-Qaeda was responsible. Yet people like Cassam are not likely to claim Olivia suffers from the epistemic vice of gullibility just because she selectively cites evidence in favour of 
her particular conspiratorial hypothesis. Why? Because ultimately Cassam's analysis rests upon the assumption belief in conspiracy theories is prima facie irrational, and so the evidential practices of conspiracy theorists must necessarily be suspect. That is, Cassam defines out-of-court the idea conspiracy theorists can be principled in their use of evidence merely because he has built into his argument that belief in conspiracy theories is generally irrational.

What seems to motivate our worry about the conspiracy theorist's use of selective evidence is our belief that conspiracies are unlikely or irrational to believe. That is to say, we judge the evidential merit of conspiracy theories on the principle that evidence for such theories must be hard to come by. Thus, the apparent and compelling evidence for a particular conspiracy theory must be the product of some kind of misrepresentation.

\section{I Checks and balances}

Given that selectiveness is a feature of the presentation of any explanation, what can we do to prevent or ameliorate problematic instances of evidence selection generally? Well, we might be tempted to think there is a sufficient check against cases of problematic selectiveness (at least in contemporary Western democracies) because we can go and inspect the pool of evidence for ourselves. That is, we do not have to take anyone's word that they have, in fact, presented all the salient evidence; if the evidence is part of the public record, then people (particularly those in positions of authority) should be less likely to be selective in their presentation of evidence because they could (and would, most of us hope) be caught.

However, this is only going to be a check against selectiveness if the consequences of being found out has repercussions. If we live in a society where such behaviour is hushed up, or even ignored, then public scrutiny might just lead to an increasing mistrust of certain kinds of authorities, thus raising fears about the likelihood of conspiracies occurring here-and-now ${ }^{\boxplus}$ After all, the CIA Inspector General's Office really did delete their only copy of 6,700 page report on the CIA's 'enhanced interrogation' programme (Gale 20I6). Whilst they claimed the deletion of this presumably damning report was a mere clerical error, the worry at the time (May 2016) was that the CIA were selectively removing publicly available evidence which would have shone a worrying light on the epistemic and moral failures of their 'enhanced interrogation' (AKA torture) programme.

\footnotetext{
3For further criticism of Cassam's argument see (Dentith in press).

${ }^{4}$ This issue will be addressed in more depth come section 8 .

5There is a common species of selective evidence in detective fiction: evidence so easily obtained it becomes obvious something has been removed/deleted/redacted in order to avoid awkward questions. Arguably this kind of evidence manipulation was central to the rationale as to the necessity of the invasion of Iraq in 2003; evidence of those pesky weapons of mass destruction was so easily
} 
slap on the wrist.

These concerns about the members of influential institutions acting selectively with respect to evidence cannot be easily pushed to one side; the conspiracy theorist's selective citation of evidence can be as principled as that of anyone else. Whilst we can charge conspiracy theorists of sometimes erroneously and selectively citing evidence in favour of their theories, we cannot claim this is a vice peculiar to them.

\section{Errant Data}

Sometimes conspiracy theorists are faulted for their reliance on evidence which is errant to some rival (often taken to be 'official') theory. Brian L. Keeley speciates out two kinds of errant data:

Errant-unaccounted-for data: Data which supports one explanatory hypothesis but is unaccounted for (is not mentioned or explained) by some rival. and:

Errant-contradictory data: Data cited in favour of one explanatory hypothesis which contradicts another, rival hypothesis (Keeley 1999).

Now, some data in the total pool of evidence will always be errant to a particular explanation; this is the principle of explanatory fuzziness. Explanations are-at least with respect to topics like history and the social sciences-fuzzy around the edges. Indeed, in most cases theories which are rivals to one another (conspiracy or otherwise) will cite some data which is errant to each other. ${ }^{⿴ 囗}$ So, the citation of errant-contrary data is no 'mark of the incredible' (to quote Keeley (Keeley 2007, p. I37)); we cannot dismiss a conspiracy theory merely because of the citation of data which supports one theory but is unaccounted for by some other.

However, the citation of contradictory data might be a problem. Normally, if we discover evidence which contradicts a particular explanatory hypothesis, then that is reason enough to reject it.

found, yet when investigated the evidence had the hallmarks of having been curated/manipulated.

${ }^{6}$ The obvious retort here would be to find examples of unprincipled citation of evidence by conspiracy theorists. However, we will find similar examples in the seemingly non-conspiratorial works of historians, scientists and politicians. Indeed, the existence of these examples are often fodder for the conspiracy theorist and her theory.

${ }^{7}$ For an analysis of the arguments as to whether conspiracy theories are in some sense unofficial, and thus rival to official theories, see (Dentith 20I4, ch. 7) and (Dentith 20I6).

${ }^{8}$ The corollary of this is that explanations in these domains which are not fuzzy-and thus take into account all the evidence-are likely post facto in nature

${ }^{9} \mathrm{~A}$ point pressed by (Coady 2006). 
Take, for example, the death of Kim Jong Nam - half-brother to the leader of the Democratic People's Republic of Korea (DPRK) - who died from VX nerve poison. This piece of evidence contradicted the official theory promulgated by the government of the DPRK, who not only claimed Kim Jong Nam died of natural causes - to wit, a heart attack - but that reports which said otherwise were the product of a conspiracy against the DPRK.

Such errant-contradictory data, though, is not a feature unique to conspiracy theories; it is also cited (or omitted) with respect to theories deemed non-conspiratorial. For example, the story told by the U.K. and the U.S. about the Iraqi regime continuing their weapon of mass destruction programme in 2003 omitted evidence which contradicted the hypothesis said weapons were still being developed by the Iraqi government.

There is no reason to think the evidence for conspiracy theories is more likely to rely on problematic instances of errant-contradictory data, unless we assume said theories are rivals to epistemically superior theories. But this would mean that the worry about contradictory data rests upon the assumption conspiracy theories are prima facie unwarranted, which we have already seen is a problematic claim. Indeed, the problem certain conspiracy theorists raise is the possibility conspirators have introduced fabricated evidence in order to make particular conspiracy theories look like they rely overly on contradictory data. That is to say, some conspiracy theorists are worried about what is commonly called 'disinformation.'

\section{Disinformation}

The term 'disinformation' (from the Russian 'dezinformatsiya') was coined by agents in the USSR in the late I930s to portray the claims of the Commission of Inquiry into the Charges Made against Leon Trotsky in the Moscow Trials (aka the Dewey Commission)that the Moscow Trials were, in fact show trials - as unwarranted. We can define 'Disinformation' as:

Disinformation: The activity of presenting fabricated or manipulated information to make some explanatory hypothesis look warranted according to the evidence when it might not be.

The use of disinformation is no idle fancy. The 'Dodgy Dossier' which allegedly justified the invasion of Iraq in 2003 really was doctored - which is to say fake 'evidence' was introduced into it and contradictory evidence omitted-by political op'erators in the U.K..

\footnotetext{
${ }^{10}$ As Sissela Bok defines it: '[A] neologism that stands for the spreading of false information to hurt adversaries' (Bok 1982, p. I87).
} 
Disinformation need not just be the product of institutional corruption or conspiracies undertaken by members of influential institutions. Individuals, for example, can disinform others. You might disinform friends about your own activities in order to ensure they do not know what you have been up to. Or you might spread disinformation about an enemy in order to ensure your friends do not like them. Sometimes you will even make it look as if some action of yours was undertaken by some other group (this is the notion of the 'false flag,' which will be discussed in section 4.3).

People, then, disinform each other all the time, yet we only seem to think this is extraordinary when conspiracy theorists talk about it. We should ask why that is.

\section{I Counterfacts and Falsifiability}

Susan Feldman presents an interesting gloss on disinformation, the analysis of which helps inform our response to claims about contradictory data being allegedly abused by conspiracy theorists. Looking at what she calls 'counterfact theories'-a kind of conspiracy theory which gets its epistemic weight from errant data-Feldman argues belief in counterfact theories is prima facie irrational (Feldman 20II). Why? Because explanations which rely on errant data are unfalsifiable, and thus irrational to believe by default.

This point has been made in stricter epistemic terms by Keeley. Unlike Feldman, Keeley argues that the apparent unfalsifiability of conspiracy theories is not a problem per se (Keeley I999). I. After all, if there really is a conspiracy in existence, then it is not unreasonable to suspect disinformation might be produced to cover it up.

Not just that, but - as I have argued elsewhere-the production of disinformation is an auxiliary hypothesis of only some conspiracy theories; it is not a feature of all of them (Dentith 20I4, ch. 8). When a conspiracy theory relies on some claim about the existence of disinformation in the evidentiary record, that auxiliary hypothesis must be assessed on its own merits. Then, and only then, can its evidential weight with respect to some conspiracy theory be calculated.

As such, Feldman is wrong to claim that conspiracy theories which suggest the production of disinformation are automatically irrational to believe. Given that errant data - both contrary and contradictory - can be a feature of any explanation, we have to assess claims about said data on a case-by-case basis. Assertions that there is disinformation in the evidentiary record are claims about how the conspirators are engaging in a particular kind of cover-up. Falsifying such a claim does not mean that there is no conspiracy. Rather, it means that this kind of evidence for the existence of a conspiracy does not apply in this particular instance.

${ }^{\text {II }}$ This point has also been discussed by both Steve Clarke (Clarke 2OO2), and (Basham 2OII). 


\subsection{Probabilities}

This leads us to an interesting worry: if you think the government has used disinformation in the past, then it is not unreasonable to suspect that they might still be producing it now.

Our notion of the independent likelihood or the prior probability of any kind of conspiratorial activity happening here-and-now depends on our beliefs about the kind of society we think we live in. If you grow up in a culture where deceit and cover-ups are commonplace, then you will be much more inclined to believe cover ups are happening; you will find claims about them elsewhere more plausible than the person who thinks they live in a largely open society. 2 Indeed, we could even say our democratic structures are-in part- the product of people creating institutions to monitor things they distrusted or found suspicious about their governments, but it is not obvious that the creation of these institutions has absolved us completely of those worries.

As such, whilst our notions of how conspired or unconspired our societies are (that is, whether or not we think conspiracies are common now ${ }^{\sqrt{3}}$ ) tells us little about the warrant of any particular, contemporary conspiracy theory, they do inform our judgements about how likely we think particular kinds of deceptive activities are. This, in turn, affects our judgements about claims of disinformation, selectiveness and the like, which then affects our notion of just how probable such activity is here-and-now. ${ }^{14}$

The history, then, of past conspiratorial activity cannot be easily swept away. The principle at stake here is that if we are going to dismiss claims of disinformation and the like, then we need some argument to the extent we have good reason to think the past incidence of conspiratorial activity tells us little about the possibility such activity is occurring here-and-now.

\subsection{Fortuitous \& Fortunate Data}

Take, for example, false flags. A false flag is an operation run by members of one political establishment designed to look like it was the actions of some other; the 'flag' of the culprits is merely a ruse.

For example, in June of 2016 - in the lead up to the U.S. presidential election-it was revealed that the Democratic National Committee (DNC) had been hacked.

\footnotetext{
${ }^{12}$ For further discussion of this, see (Basham 2OII) and (Dentith 20I6).

${ }^{13}$ Such judgments will differ from country to country, or culture to culture. We might, for example, suspect Aotearoa (New Zealand) to be a relatively benign polity compared to Romania. As such, New Zealanders might think of their country as unconspired because whilst conspiracies do occur, they occur infrequently compared to other nation states.

${ }^{14}$ For further discussion on prior probabilities and allegations of conspiracy now see (Basham 2OII) and (Dentith 20I6).
} 
The hacker (or hackers), Guccifer 2.0, claimed to be Romanian, but it was widely believed by national security experts that Guccifer 2.0 was a persona created by elements of the Russian intelligence service. That is to say, the Russian intelligence services used the 'flag' of Romania to hide the fact they were behind the hack of the DNC (Franceschi-Bicchierai 2016). I5

Now, people were suspicious about the timing of the DNC hack precisely because it was convenient for the Republican Party candidate, Donald J. Trump, whose position on Russia was considered soft compared to the Democratic Party candidate, Hillary Clinton. That is to say, it was very lucky the DNC but not the Republicans got hacked. Not just that, but the lucky nature of that data appears suspicious when we consider what occurred next; to wit, the election of a seemingly pro-Russian, American president. This, then, might be an example of what Joel Buenting and Jason Taylor call 'fortuitous data.' Such data:

i) supports the official story; but

ii) fits the official story too well; is "too good to be true" Finally,

iii) the "lucky" nature of the data is left unexplained by the official story (Buenting and Taylor 2OIO, p. 572).

Fortuitous data is purported evidence for a particular theory which is lucky in the sense the luckiness of the data suggests it has been fabricated or tampered with. For example, the official (conspiracy) theory about the attack on the Pentagon on September IIth, 200I, makes reference to a piece of what might be considered fortuitous data, the fact American Airlines Flight 77 (AA77) crashed into the only reinforced section of the Pentagon. For some, the fortuitous nature of this purported evidence requires an explanation. That is, the luckiness of the data is suspicious in such a way to suggest alternative explanations other than pure happenstance.

Yet data which is lucky might just turn out to be fortunate. 'Fortunate data,' as we might term it, is:

Data that:

i) supports some theory, and

ii) is lucky.

${ }^{15}$ The most remarked upon (and only alleged) false flag operation was the Reichstag Fire of I933, which was used by the Chancellor of Germany, Adolf Hitler, to enable emergency legislation which suspended civil liberties and allow him to round up the suspected arsonists, the Communists. This curious and convenient fact has led some to argue that the fire was a false flag event, designed to bolster the power of the Nazis in the German parliament. 
Fortunate data is merely lucky. That is, it just happens to be the case that chance swung in such a way to provide evidence which then turned out to support one particular theory. So, while it is true it was convenient for the official (conspiracy) theory of 9/I that Flight AA 77 hit the only reinforced part of the Pentagon, it really was just a matter of luck - that is to say it was fortunate - that this data supports said theory.

The problem, then, with claims about some piece of purported data being fortuitous is that it is hard a priori to distinguish between fortuitous (too lucky to be true) and fortunate (just lucky) data.

Take, for example, the purported evidence Buenting and Taylor use to motivate this talk of fortuitous data: the discovery of one of $9 / \mathrm{Ir}$ hijacker's passports in the debris around Ground Zero. They note:

That al-Sugami's passport survived the impact, ensuing fireball, and was found eighty floors below in (surprisingly) pristine condition is lucky. Moreover, that a passerby should have noticed the passport, attached significance to it, and reported the finding to an appropriate authority is fortuitous, particularly given the panic and duress one imagines those terrifying moments would have been like. All of this evidence suggests an alternative explanation, besides the explanation offered by the official story (Buenting and Taylor 2010, p. 574).

Whilst it is true the survival and discovery of al-Sugami's passport is fortuitous (in the sense that the survival of the passport-given the surrounding circumstancesis very lucky indeed) it is the fact the survival and discovery of the passport supports the official (conspiracy) theory of $9 /$ II which speaks to this admittedly unlikely event being so lucky as to be suspicious (i.e. fortuitous). That is, it is the fact the lucky nature of the data ends up supporting the official (conspiracy) theory but not the (rival) conspiracy theory that is doing the epistemic work here.

Now, what might demarcate the fortuitous from the fortunate is some claim about the luckiness of certain patterns of data; i.e. we apply our analysis of prior probabilities to the evidence at hand. For example, we might take it that the police now are-all things considered - trustworthy when it comes to presenting evidence of criminal wrongdoing. But if we were looking at a case from the context of, say, the r970s - when the planting of evidence and false convictions were more commonplace-our suspicions about how corrupt the police were then would affect our suspicions about just how fortunate, or fortuitous some data was with respect to a particular conviction. This indicates that, if we are going to be able to distinguish between fortunate and fortuitous data - between data that is lucky and data which is so-lucky-it's-not-true- then we need to focus on patterns of data which suggest the data is suspiciously fortunate. 
The problem is that we cannot principally distinguish between data which is fortuitous and data which is merely fortunate without already having made (implicitly or explicitly) some claim about the likeliness of a conspiracy (i.e. made assumptions about the pattern of data). As such, just because some data which supports a theory is lucky, that tells us nothing about whether the data is fortuitous. As such, char acterising some piece of evidence for or against a particular conspiracy theory as either fortunate or fortuitous will tend to rely upon claims about just how likely or unlikely we think conspiracies are in a given context. As we have seen, those claims have to be judged on their own merits, and thus the rationality of the principle of what demarcates the fortunate from the fortuitous in such cases is not prima facie false or unwarranted. Rather, if we are concerned about the suspicious of certain evidence when it comes to a theory-conspiracy or otherwise-we need to look at the wider context of how evidence is used or abused in our epistemic communities.

\section{Secret Evidence}

Now, not all evidence for or against conspiracy theories is manipulated. Sometimes it is cited as existing but turns out to not be examinable. That is, some of the evidence is secret.

Secret evidence: Some piece of purported evidence, where the justification for the belief that the information presented is evidence is not just unexpressed but is stated as being deliberately withheld.

For example, Donald Rumsfeld - among many other members of both the U.S. and U.K. governments - argued that the pejoratively labelled 'conspiracy theories' concerning the real reason for the invasion of Iraq in 2003 were unreasonable. Why? Because the public should trust the evidence provided in secret to the U.S. and U.K. governments by the CIA and MI6.

Now, if such evidence is not supported with other, non-secret evidence, then we should remain agnostic about its evidential weight. If the attempted debunking of any claim-conspiracy theory or otherwise-relies upon secret evidence, then it is reasonable to treat it with suspicion. Even in cases where the person citing such secret evidence appears credible and trustworthy, there is always the possibility that they are acting insincerely, are mistaken, or even have been misled by someone else.

Of course, we might want to admit in some cases of secret evidence. There will be instances where it is appropriate to hide the source of some evidence to protect said source. Intelligence agencies from one country might only be willing to share vital information with foreign powers in cases where they know said intelligence will not be leaked to the press. Information about governmental malfeasance might only come to light in cases where the source is assured of anonymity. In other cases 
we might be concerned about portions of the total evidence not being salient to the issue at hand, so we reserve the right to keep some of the evidence private or secret. However, in each of these cases a principle can be given as to why secrecy is necessary, which should-if expressed-reassure people as to why some of the evidence is being kept secret. In such cases we should also be able to point towards supporting evidence which is not secret to warrant the claim in question.

However, all this does is push the issue back one step, because the principle espoused as to why some evidence is being kept secret could be insincere and taken to be an example of evidence manipulation.

In addition, keeping some evidence secret-say, because of its confidential naturemight also be convenient. This would especially be the case if said evidence turned out to be weak but was nonetheless given weight by certain agents. Arguably, this is one argument as to why Rumsfeld and company believed they had good reason to invade Iraq; the confidential information they received weakly suggested that Iraq might still be producing weapons of mass destruction and they treated these claims are having much more evidential weight than they deserved because it was politically convenient for them 1 As such, the unexpressed nature of the justification for secret evidence-even in a case of trusting the speaker implicitly - is, at best, hesitant grounds for accepting the claim.

If there is a problem with secret evidence with respect to conspiracy theories, then, it is to do with the pattern of secret evidence used in support of such theories. However, given that secret evidence is found both in (pejoratively labelled) conspiracy theories and their rivals (and, arguably, is used more potently by public officials), we cannot claim the citation of secret evidence is an issue for conspiracy theories alone.

\section{The Worry About Evidence}

What seems to motivate our scepticism of evidence for conspiracy theories is a scepticism about the existence of conspiracies themselves; we assume they do not happen, or that they are rare. As a consequence, we introduce a high evidential threshold for conspiracy theories that we do not apply to other theories which use the same kind of evidence. This has the interesting - and it would seem pathologicalconsequence that we judge certain kinds of evidence cited in favour of conspiracy theories as unlikely or prima facie suspicious, even if the same kinds of evidence are being used in an attempt to show up said conspiracy theories. We need, then, to reorient our discussion of how conspiracy theorists use evidence to focus on the principles behind the citation of such evidence. Not just that, we need to seriously

\footnotetext{
${ }^{16}$ It is possible in such a situation that weak evidence is treated as being strong due to effects like confirmation bias and the like; we do not have to necessarily assume a conspiracy in such cases.
} 
consider why the same kind of allegedly problematic evidence is routinely used and abused in non-conspiratorial contexts without any of the opprobrium associated with conspiracy theories.

However, there are still worries about the way in which we talk about evidence generally, some of which suggest that our attitude towards evidence when it comes to conspiracy theories is problematic in a wider sense.

\section{Size \& Number}

Sometimes it is claimed belief in conspiracy theories invokes conspiracies which are so big - either with respect to how long they have been said to exist, or the number of people involved - that evidence for the conspiracy should be readily available. As such, the lack of said evidence is taken to be evidence against it. We might think of this as some claim like 'It's too big to be true!'

Take, for example, the work of Michael Barkun, whose typology of conspiracies is often cited as a reason for scepticism of big, all-embracing conspiracy theories. 7 He speciates out claims of conspiracy into three types: 'event', 'systemic' and 'superconspiracies' (Barkun 2003). 8 Belief in an event conspiracy can be rational because they concern a 'limited, discrete event or set of events ... [where] the conspiratorial forces are alleged to have focused their energies on a limited, well-defined objective' (Barkun 2003, p. 6). However, systemic - plots where the conspirators have a broad goal ${ }^{20}$ - and superconspiracies - plots which combine both event and systemic conspiracies ${ }^{2 \text {-1 }}$-are typically irrational. ${ }^{27}$ This is in part because, at least according to Barkun, they are unfalsifiable.

We have already addressed the problem with claiming conspiracy theories are unfalsifiable back in section 4.I: claiming a conspiracy theory is unfalsifiable due

\footnotetext{
${ }^{17}$ Barkun is no sceptic of conspiracies, and he accepts that some conspiracy theories have turned out to be warranted; here we are simply speaking about one aspect of his work.

${ }^{\text {I8 }}$ This kind of size criterion can also be found in the work of Juha Räikkä, who distinguishes between local, global and total conspiracy theories (Räikkä 2009); Martha Lee, who also talks about superconspiracies (Lee 20II); and Volker Heins, who also makes a similar distinction between types of conspiracies (Heins 2007).

${ }^{19}$ This view on the rationality of what Barkun calls 'event conspiracies' can be found in earlier works by (C. Pigden I995), (Keeley I999), Peter Knight (Knight 2000), and (Basham 200I).

${ }^{20}$ Such as taking control of a nation state or subverting existing institutions.

${ }^{21}$ Superconspiracies, citing ever larger conspiracies, cast into doubt any evidence for the conspiracy, since the conspirators are considered to be in the position to control and subvert the evidential record.

${ }^{22}$ Barkun's stipulation about the irrationality of belief in systemic and superconspiracies is close in kind to Popper's stipulation about the irrationality of belief in what he calls the 'conspiracy theory of society,' (Popper 1969); both Barkun and Popper ascribe to the kind of people who believe in all-embracing conspiracy theories a kind of mental pathology.
} 
to the lack of evidence for the conspiracy is an auxiliary hypothesis of only some conspiracy theories; as noted, said hypothesis must be judged on its own merits on a case-by-case basis. The fact that some conspiracy theories posit bigger conspiracies than others is not in itself evidence that said theories are unsustainable; at best it tells us that the evidential requirements for showing belief in such a conspiracy might be harder to satisfy (but not necessarily unsatisfiable).

Using a different line of argumentation, David Robert Grimes presents a mathematical model for why conspiracies of a certain size are prone to fail, and thus why belief in big conspiracy theories is irrational (Grimes 20I6). Grimes' argument centres around the viability of conspiratorial activity and how our understanding of the viability of such activity weighs upon considerations of the rationality of belief in associated conspiracy theories.

Grimes admits conspiracies occur. Indeed, he uses three examples - the NSA's Mass Surveillance programme, the Tuskegee syphilis experiment, and the FBI forensic scandal - to establish the parameters of what he considers viable conspiratorial ac ${ }^{-}$ tivity. His viability measure is a function of the time it takes for the existence of a conspiracy to be leaked, and the number of conspirators involved in the conspiracy.

To establish a best-case scenario for the viability of a conspiracy, Grimes deliberately overestimates the number of conspirators involved in his three examples. This is because the most generous estimate of the viability of those conspiracies comes out of assuming that everyone was in on it; 30,000 conspirators in the case of the NSA, 6,700 in the Tuskegee syphilis experiment, and 500 members of the FBI. He then makes two key assumptions:

I. Conspirators are generally dedicated to keeping their activity secret, or concealed.

2. Leaks by conspirators expose conspiracies, rendering the conspiracies redundant.

He then assumes that since exposure of a conspiracy via a leak should be a rare kind of event, two scenarios present themselves to explain why leaks nonetheless happen:

I. Conspirators must work at maintaining their deception, which means that, as time passes, a mistake or leak is bound to happen, and relatively quickly.

2. In the case of a conspiracy which does not need a sustained cover-up, conspirators can try to wait it out, and say nothing, which might fend off exposure for longer. ${ }^{24}$

\footnotetext{
${ }^{23}$ 'Quickly' here is measured in five year chunks.

${ }^{24} \mathrm{Grimes}$ does suggest that as time passes, conspirators are likely to start panicking about potential exposure, and thus leak regardless.
} 
There are two kinds of leak in his model: intentional (where a whistleblower or disgruntled member of the conspiracy leaks information in order to expose it) and accidental (where a conspirator fails to cover up some facet of their conspiratorial activity).

Yet the examples Grimes uses do not fit his model of conspiracies failing due to leaks. Take the NSA example; Grimes portrays Snowden as a conspirator who leaked information about the existence of PRISM and other related surveillance programmes. That certainly is one version of that story, but it is important to note that Snowden's narrative is that of being a whistleblower: an outsider-rather than a conspirator - who discovered the existence of the conspiracy.

Then there is the Tuskegee syphilis experiment. Information about the experiment was openly published in medical journals; the cover-up, so to speak, was that the patients were not told about the experiment. Once again, it was outsiders who then revealed the existence of the conspiracy. For example, Peter Buxton-who is often considered as the whistleblower in this case-came to know about the experiments because of his job with the United States Public Health Service. He was not a conspirator but, rather, a worried public official who leaked the information to the press because his worries were not taken seriously by management.

Finally, there is the case of the FBI Forensic Scandal. The 'leak' of the inadequacy of much of the forensic work undertaken by the FBI at the time did not, once again, come from a conspirator, but from someone-notably Dr. Frederic Whitehurstchecking and rechecking work. The fact that management was not willing to discuss the matter openly is what precipitated his going public about the issue.

Grimes has it that these conspiracies failed because the conspirators could not help but leak evidence of their conspiracies. Yet in his examples the conspiracies were revealed by inquisitive outsiders. There is, then, a mismatch between Grime's chosen examples, and his theory about how leaks over time revealed and made these conspiracies redundant; his examples fail to capture the very thing he wants to measure. This is a problem for both his probability estimates and his subsequent predictions about the putative viability of alleged ongoing conspiracies here-and-now.

As such, Grimes' claim that big conspiracies are unviable, and thus conspiracy theories about them are irrational, fails to get off the ground. Yet it is still instructive to look at how his model would fail to work even if he had captured the right ideas to start with.

\section{I Conspiracies Now}

Grimes wants to use his model to assess four putative conspiracy theories which posit nefarious and underhanded action by scientists, namely conspiracy theories about: 
- NASA covering up the truth of what really happened with the Moon-landing in 1969 (AKA the Moon Landing Hoax),

- Anthropogenic Climate Change,

- Vaccines causing Autism and

- the covering up of Cancer cures.

In establishing his baseline for the viability of known conspiracies Grimes was charitable: it made sense to overestimate the number of conspirators because it allowed him to establish a best-case scenario for known, exposed conspiracies. But in assessing putative conspiracies Grimes overestimates the number of people involved. According to Grimes proponents of the Moon Landing Hoax take it that everyone in NASA in the late 6os and early 70 s was complicit in the cover-up. He has effectively changed the goalposts; by using total populations - and thus assuming everyone knows - he skews the analysis by claiming 'If everyone knew, then someone should have leaked by now....'

The problem is that Grimes fails to distinguish between claims about the size of a conspiracy versus its putative structure. Grimes does not distinguish between kinds of conspirators, let alone conspirators and whistleblowers. A conspiracy can look big, yet only a small number of people involved in it might know its full extent or aim. Some members of the conspiracy will be lackeys, goons or even unwitting conspirators. Not everyone in the NSA need necessarily know that the data they are collecting and processing has been illegally obtained, and FBI agents who were using forensic evidence to secure convictions may not have been informed by senior personnel that the kind of evidence they were relying upon was of dubious merit. It is even possible to be involved in a conspiracy without realising you are conspiring. 6

As such, size really only matters once you take into account the structure of the purported set of conspirators. Once you take that into account, we encounter the problem of information hierarchies.

\section{Toxic Truths}

Lee Basham, in multiple works, discusses such information hierarchies, and introduces the notion of 'toxicity' or 'toxic truth:' evidence of a conspiracy that no one

\footnotetext{
${ }^{25}$ It is useful to note that Grimes labels Moon landing hoax theories as 'fringe,' climate change conspiracy theories as 'utterly negated by the sheer wealth of evidence against such a proposition' (Grimes 20I6, p. 3), and anti-vaccination beliefs as 'scare-mongering (Grimes 20I6, p. 3).' As such, Grimes starts out by assuming that which he wants to prove; these putative conspiracies are unviable.

${ }^{26}$ For further discussion on this topic, see (Dentith and Orr 2OI7).
} 
will touch or disseminate because of feared negative social consequences (Basham 2OII).

Take, for example, the following hypothetical. Newly discovered evidence by an investigative journalist strongly suggests the received narrative about the events of $9 / \mathrm{II}$ is not just wrong, but that members of the press and the government have been keeping this secret. The journalist approaches her editor, but is told to shelve the story; the consequences of going to print would be disastrous not just for the paper (which will be implicated as being part of the cover-up) but also for the government. If it really could be shown that the years of public discourse surrounding the events of 9/II was based on a sustained lie, then the loss of trust in the government could lead to mass civil unrest and so forth. What she has discovered is toxic, and thus for the good of the nation state it must be suppressed.

The possibility of toxic truths presents an interesting problem. We cannot necessarily appeal to authority to decide whether the evidence is good, because said authority might be interested in downplaying the evidence. However, an appeal to the evidence itself would be just as troubling, because if it is toxic, then we should expect disinformation to be produced about the centrality or salience of said evidence. Not just that: there will be arguments to the extent that the evidence is the result of selective tampering in the pool of evidence, or other evidence will be used selectively to show up said toxic truth. Sorting out the evidence from the non-evidence in a case like this is no trivial task.

\section{I The Polite Society}

One reply would be to say that the non-reporting of such evidence might just be because it has been politely ignored or downplayed by the populace. By 'polite' we mean here something like 'It is just not talked about:' some seemingly toxic truths might just be the polite fictions we employ to ensure the smooth running of our society. Toxic truths, after all, imply a cover-up which is top-down: journalists; politicians; the judiciary; and the police conspire to stop certain truths escaping into or infecting the polity. Politeness, however, suggests that sometimes we engage in 'coverups' (so to speak) from the bottom-up by ignoring certain problems or patterns of behaviour in our societies. So, for example, many citizens of the I970s knew the police were planting evidence to secure convictions, but ignored the situation because they trusted that the police were targeting the right kind of people.

Politeness and toxicity are all a matter of degree and context; some things are politely ignored ${ }^{\text {五 }}$ and some things are kept secret because letting the public learn

\footnotetext{
${ }^{27}$ For example, institutionalised racism and sexism, historically, has been brought to the public's attention but not acted upon/been politely ignored. For the victims of such discrimination, at least, this can look very much like a society trying to cover things up and act as if everything is normal.
} 
the truth about them would be damaging. 28

Politeness - in the sense discussed here-is a complimentary thesis to toxicity. Both analyses - toxicity and politeness - can be true at once in a given society; some evidence might be politely ignored by the populace and some of it might be so toxic as to require an active cover-up. After all, in defence of an analysis through the lens of toxicity, it is hard to dispute that our society is more conspired than we think. 20. Sometimes politeness will be used an excuse for not revealing evidence which turns out to be toxic. After all, what better way to shut down a story than by telling a journalist 'Don't bother reporting that; everybody knows, but no one cares about it!' Claiming some terrible crime will be politely ignored is just another way to cover it up.

The principle behind both toxicity and politeness is secure; there are certain truths about society which might be considered unspeakable, whether that be by edict from on high or by popularity. We cannot expect that evidence of a conspiracyor indeed any kind of wrongdoing - will be automatically the subject of popular opprobrium. Indeed, given the continuing tendency to downplay the seriousness of sexual assault, the unwillingness by governments to acknowledge - let alone addressshocking inequalities in our societies, this shows that a certain amount of politeness or aversion to toxicity is still a factor in society today; we do not need to talk about conspiracies or conspiracy theories to illustrate that. 俩

\section{Conclusion}

When looking at how evidence gets used both in the support and condemnation of conspiracy theories, it turns out we cannot justify the claim conspiracy theorists have lax evidential standards compared to the rest of us. Indeed, the kinds of evidence cited in support of conspiracy theories are also routinely found and cited in support in theories which are not considered conspiratorial. It is interesting that we do not typically find such evidence or evidential practices to be problematic in those cases; we seem to have introduced a high evidential threshold for conspiracy theories that we do not typically apply to other theories.

Yet when we consider the principles behind the seemingly suspicious kinds of evidence associated with conspiracy theories, we find that the evidentiary practices

\footnotetext{
${ }^{28}$ This, at least, was the rationale behind the cover-up of the 'Unfortunate Experiment' in Aotearoa (New Zealand), where women who had been diagnosed with cervical cancer were not informed that they were taking part in a clinical trial and being deliberately under-treated. The whistleblowers were ignored by the authorities because to act upon that information would have lead to a loss of trust by the public in the medical profession.

${ }^{29}$ As previously mentioned, see (Dentith 20I6).

${ }^{30}$ Indeed, many of the activities we suspect ground our belief in the existence of conspiracies are open secrets, some of which we just politely ignore, or downplay (see (Dentith and Orr 20I7)).
} 
of the conspiracy theorist are not necessarily fallacious. None of this is to say that conspiracy theorists are exemplary reasoners; no one denies that there is spurious or fallacious belief in some conspiracy theories. However, if we are to investigate belief in conspiracy theories, we cannot start from a position of assuming conspiracy theorists are automatically at fault when it comes to evidential concerns. That -as we have seen-goes against the (available) evidence. 


\section{References}

Barkun, Michael (2003), A Culture of Conspiracy: Apocalyptic Visions in Contemporary America, University of California Press, Berkeley, California.

Basham, Lee (in press), "Joining the Conspiracy", Argumenta.

- (200I), "Living With The Conspiracy", The Philosophical Forum, XXXII, 3, pp. $265^{-}$ 280.

- (20II), "Conspiracy Theory and Rationality", in Beyond Rationality, ed. by Carl Jensen and Rom Harré, Cambridge Scholars Publishing, Newcastle on Tyne, chap. 4, pp. 49-87.

Bok, Sissela (1982), Secrets. On the Ethics of Concealment and Revelation, Pantheon Books, New York, ISBN: O-394-5158I-I.

Buenting, Joel and Jason Taylor (2010), "Conspiracy Theories and Fortuitous Data", Philosophy of the Social Sciences, 40, 4, pp. 567-578, DOI: $10.1177 / 00483931093507$ 50.

Cassam, Quassim (2015), Bad thinkers, ed. by Brigid Hains, Mar. 2015, http : / / ae on . co / magazine / philosophy / intel lectual - character - of - conspiracy theorists/.

- (2016), "Vice Epistemology", The Monist, 99, pp. I59-I80, DOI: 10.1093/monist/ onv034.

Clarke, Steve (2002), “Conspiracy Theories and Conspiracy Theorizing”, Philosophy of the Social Sciences, 32, 2, pp. I3 $\mathrm{I}^{-} \mathrm{I} 5 \mathrm{O}$.

Coady, David (2006), "Conspiracy Theories and Official Stories", in Conspiracy Theories: The Philosophical Debate, ed. by David Coady, Ashgate, Hampshire, England, chap. 9, pp. II5-I28.

- (2OI2), What to believe now : applying epistemology to contemporary issues, Wiley-Blackwell, Chichester, West Sussex.

Dentith, Matthew R. X. (in press), “The Problem of Conspiracism”, Argumenta.

- (20I4), The Philosophy of Conspiracy Theories, Palgrave Macmillan, ISBN: 978- ${ }^{-}{ }^{-} 37^{-}$ 36315-2, DOI: $10.1057 / 9781137363169$.

- (2016), "When inferring to a conspiracy might be the best explanation", Social Epistemology, 30 (5-6 2016), pp. 572-59I, DOI: 10.1080/02691728.2016.1172362.

Dentith, Matthew R. X. and Martin Orr (2017), "Secrecy and Conspiracy", Episteme, DOI: $10.1017 /$ epi . 2017.9.

Feldman, Susan (2OII), "Counterfact Conspiracy Theories", International fournal of Applied Philosophy, 25, I, pp. 15-24, IssN: 0738-098X.

Franceschi-Bicchierai, Lorenzo (2016), “'Guccifer 2.0’ Is Likely a Russian Government Attempt to Cover Up Its Own Hack", Vice (June 20I6), https : / / mothe rboard.vice.com/en_us/article/guccifer-20-is-likely-a-russiangovernment-attempt-to-cover-up-their-own-hack. 
Gale, Sadie Levy (2016), "CIA 'mistakenly' destroys copy of 6,700-page US torture report", The Independent (May 2016), http: //www . independent . co.uk/news / wo rld/americas/cia-mistakenly-destroys-copy-of-6700-page-us-torturereport-feinstein-a7034096.html.

Grimes, David Robert (20I6), "On the Viability of Conspiratorial Beliefs", PLOS One, II, I (Jan. 20I6), DOI: 10.1371/ journal . pone.0147905.

Heins, Volker (2007), "Critical theory and the traps of conspiracy thinking", Philos ophy Social Criticism, 33, 7, pp. 787-80I, DOI: 10.1177/0191453707081675.

Keeley, Brian L. (I999), "Of Conspiracy Theories”, The fournal of Philosophy, 96, 3, pp. 109-126.

- (2007), "God as the Ultimate Conspiracy Theorist", Episteme, 4, 2, pp. 135-49.

Knight, Peter (200o), Conspiracy Culture: From the Kennedy Assassination to The X-Files, Routledge, London.

Lee, Martha F. (201I), Conspiracy Rising: Conspiracy Thinking and American Public Life, Praegar, Santa Barbara, California.

Pigden, Charles (I995), "Popper Revisited, or What Is Wrong With Conspiracy Theories?", Philosophy of the Social Sciences, 25, I (Mar. 1995), pp. 3-34, DOI: $10.1177 /$ 004839319502500101.

Pigden, Charles R. (in press), "Conspiracy Theories and the Conventional Wisdom Revisited", in Secrets and Conspiracies, ed. by Olli Loukola, Rodopi, in press.

- (2016), "Are Conspiracy Theorists Epistemically Vicious?", in Blackwell Companion to Applied Philosophy, ed. by David Coady, Kimberley Brownlee, and Kasper Lipper-Rasmussen, Wiley-Blackwell, chap. 9, pp. I20-I32, ISBN: 978-III8869I30, DOI: $10.1002 / 9781118869109 . \mathrm{ch} 9$.

Popper, Karl Raimond (1969), The Open Society and Its Enemies, 5th, Routledge and Kegan Paul, London and Henley, vol. 2.

Räikkä, Juha (2009), "The Ethics of Conspiracy Theorizing”, The fournal of Value Inquiry, 43, pp. 457-468, DOI: $10.1007 / \mathrm{s} 10790-009-9189-1$.

Warburton, Nigel and Quassim Cassam (2015), 2uassim Cassam on Conspiracy Theories, Philosophy Bites, May 2015, http://philosophybites.com/2015/05/quassimcassam-on-conspiracy-theories.html. 